\title{
Auto representações de uma professora de língua inglesa ${ }^{1}$ Self-representations of an English teacher
}

\author{
Natália Mariloli Santos Giarola*
}

\begin{abstract}
RESUMO: $O$ presente trabalho aborda a formação de professores na área de Linguística Aplicada buscando analisar dizeres a partir da teoria do discurso atravessada pela psicanálise freud-lacaniana. Nessa abordagem, o sujeito é visto como heterogêneo, dividido pelo inconsciente e afetado pela linguagem, em busca da completude e unidade que, por serem da ordem do impossível, permitem constantes questionamentos e transformações. O sujeitoprofessor passa por deslocamentos identitários quando busca se tornar um professor de língua estrangeira (LE) e passa a se identificar como portador de um saber que o distingue das outras pessoas. Neste trabalho, focalizamos em algumas representações de uma professora de Língua Inglesa (LI) sobre si como educadora, e utilizamos recortes de um corpus maior para o desenvolvimento das análises. Os instrumentos utilizados para formação do corpus foram o diário de notas da professora, entrevistas semiestruturadas e notas de campo. Os dados foram organizados a partir de temas surgidos desses dizeres. Percebemos que a docente representa-se como frustrada e insatisfeita com o seu próprio conhecimento da LI, com a desvalorização do professor e com sua falta de autoridade em sala de aula. Ela também se compara aos outros professores, buscando, como sujeito desejante e implicada na formação continuada, se aproximar de uma imagem de si mais proficiente e mais preparada

ABSTRACT: This paper approaches teachers formation in Applied Linguistic area in order to analyze sayings through discourse theory crossed by Freud-Lacan psychoanalysis. In this approach, the subject is heterogeneous, divided by the unconscious and affected by language, aiming wholeness and unity that are impossible, but they allow questioning and transformation. The teacher goes through identity shifts when he/she seeks to become a foreign language teacher and starts to selfidentify as having knowledge that distinguishes from the others. In this paper, we focus on some auto representations of an English teacher as an educator, and we used cutouts of a larger corpus for analysis' development, in which we used as methodology: teacher's daily notes, semistructured interviews, and field notes. The corpus were organized from themes that emerged in the sayings. We noticed that the educator represents herself as frustrated and dissatisfied with her own English knowledge, the teacher's devaluation, and lack of authority in the classroom. She also compares herself with other teachers, aiming to approach an image of herself as more proficient and more prepared methodologically because she is involved on continuing education. This study may contribute to discuss the teachers' formation because we discuss relevant issues that may make teachers to confront with the representations that they give to themselves.
\end{abstract} metodologicamente. Este estudo pode contribuir para problematizar a formação de professores, pois discutimos temas que podem fazer com que os docentes se confrontem com os significantes que eles se atribuem ao se

\footnotetext{
${ }^{1}$ Este artigo é resultado de um recorte do corpus de minha dissertação de mestrado.

* Mestranda em Estudos Linguísticos, Faculdade Letras, Universidade Federal de Minas Gerais (UFMG).
} 
dizerem professores e falantes de língua

estrangeira.

PALAVRAS-CHAVE: Representações.

Professor de Língua Inglesa. Prática KEYWORDS: Representations. English Pedagógica.

Teacher. Pedagogical Practice.

\section{Introdução}

A área da Linguística Aplicada (LA) é ampla e transdisciplinar (CLARK, 2000; ROJO, 2006; SZUNDY; NICOLAIDES, 2013) possibilitando, desse modo, a comunicação com outras áreas e campos do saber que também tratam de questões sobre os usos sociais da linguagem. Nesse sentido, Signorini (1998, p. 99) reforça que a LA é "como uma espécie de interface que avança por zonas fronteiriças e como uma área que produz conhecimento próprio ao ressignificar os conceitos utilizados para compreender os usos da linguagem nas mais diversas esferas sociais".

Por isso, alguns estudos que levam em conta a vertente discursiva têm ganhado destaque através da contribuição de autores como CORACINI (2011); FERREIRA, (2003); LOURES (2014); MARIANI (1999); NEVES (2002); RIOLFI (1999; 2015); SÓL (2014); TAVARES (2010), entre outros pesquisadores que fundamentam os olhares de novos investigadores. A vertente discursiva nos dá possibilidade de discutir, sobretudo, a noção de sujeito heterogêneo, dividido entre o consciente e o inconsciente e constituído pela linguagem, uma vez que ele é inacabado, possui furos e não fica preso nas estruturas; além de o inconsciente influenciar suas atitudes no dia a dia. Desse modo, o sujeito faz parte do ato comunicacional, inscrevendo-se na linguagem como efeito desta, produzindo sentidos sócio-historicamente situados, sempre esbarrando no real da língua que é da ordem do indizível, impossível de simbolizar. Conforme Orlandi (1999), o que não se submete à linguagem se caracteriza como falha, acaso, equívoco e não se submete à regra. É o real que possibilita a deriva, o deslize e o efeito metafórico dos sentidos. Por isso, a linguagem que constitui o sujeito "deixa sempre um furo, uma falta, [e o] sujeito tentará infinitamente preenchê-la, simbolizando elementos diversos, numa busca constante de completude" (FREITAS, 2009, p. 74).

Neste artigo, abordamos questões da Linguística Aplicada buscando interpretações fundamentadas na Análise do Discurso (AD) considerada no atravessamento da psicanálise lacaniana. Nosso objetivo é apresentar a investigação que fizemos e os resultados encontrados ao buscarmos compreender como uma professora de uma escola pública, participante do projeto 
ConCol (Continuação Colaborativa) da Universidade Federal de Minas Gerais (UFMG), se representa como professora de língua inglesa (LI) e como isso afeta sua prática pedagógica.

Ao abordarmos o sujeito-professor e o seu discurso a fim de identificar dizeres que nos levam a depreender representações da professora participante da pesquisa, também apontamos o percurso metodológico utilizado para formação do corpus, a sua análise e a obtenção dos resultados. Esperamos que todo o trajeto seja relevante para a formação continuada de professores de línguas estrangeiras.

\section{O sujeito-professor e sua incompletude}

Os estudos sobre o sujeito-professor de línguas estrangeiras vêm se desenvolvendo consideravelmente como um espaço amplo para pesquisas na área de Linguística Aplicada (doravante, LA) e no campo da educação. A Análise do Discurso (doravante, AD) atravessada pela Psicanálise Lacaniana juntamente com os estudos da Enunciação podem oferecer um campo fértil de investigação das questões que afetam esse professor.

A noção de sujeito que utilizamos advém da $\mathrm{AD}$ afetada pela Psicanálise, nas quais o sujeito não tido como unificado, ele é descentrado e inacabado, visto que ele é "sempre refeito de acordo com as relações sociais que estabelece, pois são essas relações, as relações com o outro da linguagem, que [o] levam a se construir como tal" (PEREIRA; SANTIAGO; LOPES, 2009, p. 144). Além disso, ele é dividido, atravessado pelo inconsciente e sócio-historicamente construído (ORLANDI, 1999). Portanto, assumimos que o professor se constitui na sua relação com os alunos, com os outros professores e outras pessoas, todos inseridos numa dada cultura e, com isso, ele está sempre a se construir, visto que a formação do eu é a partir da relação/olhar do outro (CABAS, 2009). Ou melhor, a constituição identitária do sujeito está sempre em transformação e ela é formada por meio das experiências pessoais e das experiências dos Outros que o cercam, concedendo-lhe singularidade. Assim, a identidade é afetada pela alteridade, uma vez que "ela se pauta, em grande parte, no desejo de corresponder ao desejo do outro, de ser amado pelo outro, de ser por ele reconhecido" (TAVARES, 2010, p. 98).

$\mathrm{Na} \mathrm{AD}$, o sujeito pode ocupar várias "posições-sujeito" em seu discurso, além de a psicanálise o tomar como sujeito da falta, sujeito desejante que está sempre em busca de uma completude ideal. Podemos dizer, então, que o professor de línguas estrangeiras busca um ideal de competência linguística e de metodologia para o seu ensino, de maneira especial, aquele que participa de projetos de educação continuada (EC), visto que eles vão em busca de completude, 
de possíveis soluções para os desafios encontrados na sala de aula. Em geral, espera-se que, ao chegar a um curso de Educação Continuada (doravante EC), esse professor anseie por soluções para seus questionamentos e frustrações, além de buscar, pela via do desejo ${ }^{2}$, teorias para melhorar e/ou compreender melhor suas práticas pedagógicas.

Podemos, ainda, assumir que o sujeito-professor pode ser considerado um sujeito que se encontra na transição entre o moderno e o pós-moderno, concepção na qual, segundo Coracini (2003), a identidade é atravessada por uma multiplicidade de vozes, sempre incompleta e em formação. Nessa concepção, ser falante de outra língua pode causar deslocamentos identitários, visto que "aprender uma língua estrangeira é sempre, um pouco, tornar-se um outro" (REVUZ, 1998, p. 227). Por isso, o sujeito-professor, quando busca aprender e se tornar um professor de língua estrangeira, procura se identificar, mesmo que implicitamente, como portador de um saber que o distingue das outras pessoas e o faz pertencer "a um grupo seleto, muitas vezes idealizado, daqueles que sabem outra língua, frequentemente identificada por atributos que a destacam da língua materna" (TAVARES, 2010, p. 99).

Com isso, é fundamental abordarmos o conceito de identidade. Segundo Coracini (2007), a identidade está sempre em transformação e o sujeito se vê pelo olhar do Outro ${ }^{3}$. Além disso, ele é formado por meio das experiências pessoais e das experiências dos outros que o cercam. Assim, a constituição identitária é afetada pela alteridade, uma vez que "ela se pauta, em grande parte, no desejo de corresponder ao desejo do outro, de ser amado pelo outro, de ser por ele reconhecido" (TAVARES, 2010, p. 98).

A identidade também está relacionada ao conceito de narcisismo, uma vez que o sujeito busca a atenção e o reconhecimento do outro, nutrindo uma paixão por si mesmo, na tentativa de constituição do eu. Desse modo, o narcisismo é visto "como elemento constitutivo do amorpróprio e da autoestima e, portanto, destinado à autopreservação do sujeito e formação dos laços sociais" (ARAÚJO, 2010, p. 79). Buscamos primordialmente em Freud (1914) conceitos importantes para a análise do corpus deste artigo, uma vez que abordamos sobre a identificação de Sofia com outros sujeitos, levando-a desejar ser semelhante ao outro: (1) o eu ideal que está ligado ao estado narcísico e o (2) ideal do eu que envolve um modelo ao qual o sujeito procura

\footnotetext{
${ }^{2}$ Este desejo está relacionado a uma falta. Além dele ser a "realização de um anseio ou voto inconsciente" (ROUDINESCO; PLON, 1998, p. 146).

${ }^{3}$ Esse Outro é o Outro simbólico, o Outro da referência, no qual "sofre interferência tanto da sociedade quanto da estrutura familiar do sujeito. [...] Ele é um Outro que vai sendo internalizado pelo sujeito até se tornar o seu parceiro mais íntimo" (MRECH, 2003, p. 136). Desse modo, ele pode ser os pais, a cultura, as pessoas ao redor; enfim, é o tesouro dos significantes.
} 
seguir para ser amado e reconhecido e "o que ele projeta diante de si como seu ideal é o substituto para o narcisismo perdido na infância, na qual [na infância] ele era seu próprio ideal" (FREUD, 1914, p. 27).

Em seguida, abordaremos as noções de representação utilizadas em nosso estudo, a fim de contribuir para a análise de nosso corpus.

\section{Do discurso às representações do sujeito}

Pelo viés da vertente discursiva, entendemos que o discurso permite compreender a produção de sentidos e as relações entre os sujeitos na sociedade. Neste artigo, atentamos não só para os enunciados, mas também para a enunciação da professora, nos quais buscamos apreender as representações que ela faz de si mesma como professora de língua inglesa, pois todo sujeito pode se colocar no lugar do interlocutor, podendo alterar seu discurso devido à maneira como quer atingir o ouvinte.

Por isso, Tavares (2010) traz para a questão do enunciado também a enunciação, uma vez que a autora trabalha com a noção de sujeito da enunciação na qual o sujeito "é o resultado do atravessamento do inconsciente na linguagem, da dissonância entre o que se pensa ser e o que se diz ser, da brecha que se abre pelo equívoco e que deixa escapar algo que não se sabia” (TAVARES, 2010, p. 65). Desse modo, apoiamo-nos em Tavares (2010), quando ela afirma que a constituição identitária do professor de LE pode se dar por meio das representações construídas a partir de certos discursos, visto que o sujeito, inconscientemente, assume diferentes posições em determinado lugar discursivo. Por exemplo, o professor pode se posicionar discursivamente ora como aluno, ora como professor de LI ou participante de um programa de EC.

Além disso, o trabalho com os dizeres do sujeito-professor nos possibilita identificar as representações desse sujeito, contribuindo significativamente para as pesquisas que tratam de questões identitárias importantes para uma reflexão dos futuros professores em formação universitária e daqueles que já se encontram em serviço.

Conforme Neves (2002), as representações são constituídas no interdiscurso, são dinâmicas, mudam o tempo todo, acontecendo via (des)identificação. Elas estão relacionadas às imagens que o sujeito faz do mundo. Aliás, no ponto de vista de Tavares (2010, p.129), as representações também são modos de interpretação da realidade que podem ser notadas por meio de "imagens, enunciados ou signos, o que não implica uma apreensão fiel da realidade". 
Além do mais, quando o sujeito fala, ele se apropria da linguagem instaurando a sua subjetividade e é por isso que podemos depreender os possíveis deslocamentos na constituição identitária do sujeito.

Esses conceitos serviram de base para a formação do corpus e dos nossos gestos de interpretação abordados a seguir.

\section{Condições de produção do corpus}

Buscando subsídio nas pesquisas em Ciências Sociais e Humanas para a construção das ferramentas metodológicas de nossa investigação, tomamos como referência o estudo de caso envolvendo apenas uma participante. Desse modo, mesmo podendo ter um relacionamento direto e pessoal com ela, lembramos que a nossa noção de subjetividade é 'não subjetivista' pois é constituída no discurso, "no lugar e na posição discursiva relativa a um efeito da memória, espaço aberto de significantes e instância de constituição dos sentidos" (NEVES; REIS, 2009, p. 234). De acordo com Duff (2012), o estudo de caso permite maior flexibilidade no modo de desenvolver a análise, além de exemplificar uma situação de maneira concreta e imediata. O objetivo do estudo de caso é particularizar e voltar a atenção para o que tem significância teórica, envolvendo diferentes unidades de análises. Este método de pesquisa "surge do desejo de entender fenômenos sociais complexos" (YIN, 2014, p.4) e geralmente as perguntas principais são formadas por "Como?" ou "Por quê?".

Para formar o corpus deste estudo, convidamos uma professora de língua inglesa, que atua em uma escola estadual da região de Contagem, Minas Gerais (MG), e participa do grupo de educação continuada, o ConCol da Universidade Federal de Minas Gerais, desde 2012. Ela graduou-se em Letras, em 1999, em uma faculdade privada e leciona inglês no contexto escolar público desde 2001. Ela possui 16 turmas do $7^{\circ}$ ano do ensino fundamental ao $1^{\circ}$ ano do ensino médio, no período matutino. E, geralmente, suas salas de aula possuem mais de 35 alunos.

Este trabalho é um recorte de um estudo maior que utilizou os seguintes instrumentos para formação do corpus: (1) diário de notas da professora, no qual a docente escreveu, semanalmente, suas impressões das aulas e da sua participação no ConCol. Com o objetivo de assegurar que a sua escrita fosse mobilizadora, uma explicação geral foi previamente fornecida à participante a fim de se ter um texto marcado de sua responsabilidade social pelo que escreve e que a implicasse subjetivamente (GRIGOLETTO, 2011). Julgamos necessário utilizar (2) entrevistas semiestruturadas, a fim de esclarecer possíveis dúvidas surgidas a partir da análise 
dos instrumentos de formação do corpus; dar a chance para a professora explicar suas anotações e, finalmente, dar oportunidade para registrarmos momentos de enunciação. Também usamos (3) notas de campo que, segundo Bogdan e Biklen (1994), são as informações escritas sobre o que o pesquisador observa, ouve e experiencia durante o contexto de pesquisa. Além disso, fizemos observações de aulas da professora, uma vez que elas são necessárias para que o pesquisador possa documentar suas interpretações a respeito das aulas da professora, tomadas como relevantes para a investigação.

Como exigências para a análise, tomamos sugestões de Michel Pêcheux em sua obra $O$ Discurso: estrutura ou acontecimento (2002). Ele sugere que se descrevam as materialidades linguísticas e, em seguida, reconheçam nelas aquilo que rompe as significações estabilizadas. Desse modo, e lembrando que para este artigo trazemos somente um recorte de uma pesquisa mais extensa, analisamos a materialidade dos dizeres da professora participante, para chegarmos a algumas de suas representações como educadora.

\section{Interpretando o corpus: como o sujeito-professor se vê?}

Durante a formação do corpus, fomos marcando, na materialidade que a pesquisada produzia, os indícios que nos levavam às tomadas de posição da professora. Notamos indícios de insatisfação com o seu próprio conhecimento da língua inglesa, principalmente no que se refere à habilidade oral. Em posição de queixa, ela alegava que ainda não havia tido oportunidade de fazer nenhum intercâmbio e reclamava da desvalorização do professor, de modo a reverberar, na fala e na escrita, dizeres de uma memória social corrente no discurso da mídia brasileira, por exemplo. As referências ao intercâmbio são reverberações de discussões surgidas nos encontros da EC, de colegas que já haviam viajado aos Estados Unidos com bolsas da Fulbright ${ }^{4}$ ou mesmo em função do discurso da mídia e do governo brasileiro ${ }^{5}$ sobre a oferta de bolsas para cursos no exterior para professores da rede pública. Além disso, como podemos ver no que ressoa em seus dizeres abaixo, ela diz de seu interesse em ser semelhante aos colegas, indiciando o desejo de desenvolver bons projetos na escola e se esforçando para se expressar com mais desenvoltura na língua alvo. Vejamos, nos dizeres abaixo, como ela se posiciona:

\footnotetext{
${ }^{4}$ Fulbright é uma organização internacional vinculada ao governo dos Estados Unidos da América que proporciona programas de intercâmbio educacional e cultural (http://fulbright.org.br).

5 Por exemplo o programa ILEP (Líderes Internacionais em Educação) http://portuguese.brazil.usembassy.gov/diretores.html.
} 
(1) Mas meu inglês não é fluente quanto o da X. Você está me entendendo?/ Aí tem barra na língua $(26 / 06 / 2014)$.

(2) Eu fico me comparando aos outros professores, por que eles conseguem [disciplina] e eu não?! (07/08/2015).

(3) Eu quero trabalhar mais perto deles [alunos], sabe. / Ser a professora que tava lá. / Ela não serei, porque cada pessoa tem sua característica/ mas a professora que faz jogos $/ / /$ sabe, com os meninos. Os meninos estão próximos dela, ter o prazer de estar na aula" (28/08/2015).

No recorte (1), a docente inicia a sua fala com uma oração adversativa, evidenciando uma insatisfação em relação ao que acabara de dizer e se comparando de modo a se inferiorizar diante da proficiência linguística de outra professora. Nos demais recortes, ela também se compara aos colegas em relação à prática pedagógica e ao controle e disciplina dos alunos. Nos três recortes, é destacável a negativa que sinaliza sua impotência em fazer como o outro faz, em saber como o outro sabe. O mal-estar e a insatisfação prevalecem nessa fala. Ou seja, ela se identifica com os colegas, principalmente em relação ao que percebe ser o prazer do docente: um saber que não se sabe, isto é, o saber inconsciente, que não damos conta dele. Isto ocorre, uma vez que "aquilo com que o sujeito se identifica é aquilo que ele quer ser" (OGILVIE, 1991, p. 118). Lacan ([1966] 1998) trabalha a noção de identificação por meio da conceituação do estádio do espelho, no qual a criança é formada pelo olhar do Outro, isto é, o pequeno ser, quando é confrontado com o espelho através do adulto que medeia esse confronto, adota uma imagem de si como o seu "eu" e se reconhece por meio dessa imagem de si. Consequentemente, a constituição do "eu" ideal ocorre na infância, quando o sujeito assume uma primeira identificação pela qual outras identificações serão constituídas durante sua vida (LACAN, [1964] 1998).

Entretanto, como sujeito desejante e implicado na formação continuada, a posição tomada pela docente é a de se aproximar da imagem que faz de si como mais proficiente e mais preparada metodologicamente, agindo de forma a tentar sê-lo, a despeito de suas resistências ${ }^{6}$ (FREUD, [1895] 1996; ROUDINESCO; PLON, 1998). Com isso, observamos que ela procura se afinar com o ideal do projeto e dos formadores e assim se mostra empenhada em fazer cursos

\footnotetext{
${ }^{6}$ Resistência é uma expressão usada pela Psicanálise para se referir aos obstáculos (rejeição) criados pelo sujeito quando ele está em análise. Além disso, ela é um dado clínico (Roudinesco e Plon, 1998).
} 
de LI para melhorar sua competência linguística, não falta aos encontros da EC e demonstra ter vontade de estudar e praticar mais a língua inglesa num país onde ela é falada como língua materna, o que acredita ser a melhor forma de se autorizar como falante fluente. Assim, conforme Coracini (2003), o professor de língua estrangeira se constitui e é afetado pela alteridade e pelo estranhamento de si diante do outro. À medida que ele tem contato com outras culturas, ele consegue perceber o estrangeiro que o habita. Portanto, "o ensino e a aprendizagem de uma LE inserem o sujeito em outra discursividade, sem, entretanto, eliminar aquela que o constituiu, que é a de sua língua materna" (BOLOGNINI, 2003, p.192). Assim, a pesquisada vai buscando depreender a constituição identitária da professora Sofia sem, contudo, alcançála plenamente.

A partir dos dizeres da professora, podemos identificar o "eu-ideal" que se constitui no imaginário como uma identidade una. Conforme Orlandi (1999), o imaginário faz parte do funcionamento da linguagem e envolve relações históricas, políticas, sociais e de relações de poder. Desse modo, as representações do sujeito, muitas vezes, são passíveis de verificação por meio da sua enunciação, uma vez que elas "podem ser compreendidas como identificações flagradas no discurso e que, portanto, sugerem processos identificatórios" (NEVES; HON; REIS; EVANGELISTA, 2013, p. 197).

Por meio da enunciação da participante, podemos depreender representações próprias da incompletude subjetiva que, justamente por ser animada pela falta, lugar do desejo, segundo Lacan, permitem reflexões e transformações do sujeito. Como se pode observar nos dizeres a seguir, a colaboradora, que nos dizeres anteriores havia se colocado no lugar da queixa e da impotência, compara-se novamente a outra colega, dando sinais, também por meio do seu tom de voz e expressão, de querer melhorar sua prática e relacionamento com os aprendizes:

(4) "Uma professora do interior, ela tinha disciplina, o problema era indisciplina, mas ela conseguia com as turmas/ fazer os jogos /e no final de ano ela leva os meninos que tiveram as melhores notas, a equipe vencedora num clube. [...] Aí, eu tenho vontade de fazer essas coisas, sabe? Preciso

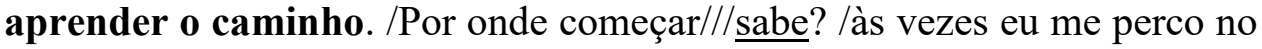
caminho, o caminho" (28/08/2015).

Nesse dizer, em mais uma comparação que faz entre si e uma colega docente, ela se coloca na posição de aluna, quando ressalta, de modo deôntico, (preciso), a necessidade de "aprender o caminho", para lidar com a indisciplina e as demais dificuldades encontradas em 
sala de aula. O uso da metáfora "caminho", sugerindo que saber lidar com a indisciplina tenha uma direção certa na qual o sujeito não pode se perder se a segue corretamente, é um forte indício do seu mal-estar em acreditar que haja um único jeito de fazê-lo e só o outro sabe. É comum, no espaço da EC, ouvirmos de muitos professores de escolas regulares, reclamações de que seus alunos não se interessam pelas aulas e que há muita indisciplina. Essas queixas refletem o mal-estar social, considerado sintoma na concepção da psicanálise, que paralisa o professor. Torna-se uma cadeia que se repete, fechada nos pressupostos de: professores impotentes que não sabem ensinar e de alunos-problema que não aprendem, como afirmam as psicanalistas Margarete Miranda e Ana Lydia Santiago (2010, p. 1).

Uma marca enunciativa que reverbera no dizer da professora-participante é a recorrência do verbo "saber", a fim de buscar o Outro para o seu dizer. Ela busca identificação, no sentido de questionar com o interlocutor se ele o identifica com ela, se ele sabe do que ela está falando e compartilha do seu não-saber.

Como nos alerta Sól (2014), as queixas e manifestações de angústia devem ser valorizadas e ouvidas, pois o sujeito tem muito "a 'se' dizer". Nesse sentido, muitos professores participam de cursos de educação continuada com o objetivo de superar os problemas que vivenciam em suas salas de aula, como, por exemplo, a falta de maior conhecimento linguístico da língua estrangeira e metodologias de ensino, além de almejarem uma articulação com a universidade e de serem mais valorizados pela comunidade escolar. No entanto, há o perigo de que o grupo se mantenha na circularidade do discurso, ou seja, ficar apenas na queixa, na fala vazia das reclamações.

No campo da educação, discute-se que cada educador reflete e ressignifica ou não suas práticas pedagógicas em seu próprio tempo e ele também tem a difícil tarefa de compreender os estágios e desejos dos alunos na escola de hoje. De acordo com Lacan (1998), há um tempo lógico de cada sujeito que se diferencia do tempo cronológico/quantitativo. Esse tempo se divide em três momentos: "o instante do olhar", "o tempo para compreender" e "o momento de concluir". Cada sujeito precisa de um tempo para vivenciar, criar e ressignificar suas experiências. Portanto, podemos observar que a professora está no primeiro estágio do tempo lógico, o instante do olhar. Segundo Miranda e Santiago (2010, p. 4), "no instante do olhar para o problema, uma subjetivação se modula: o sujeito impessoal recíproco", isto é, a pesquisada está ainda no instante do olhar quando adota uma impessoalidade em relação aos problemas: pela negação, marca a sua incapacidade, não se implica na problemática e responsabiliza o 
Outro por seus fracassos, como vemos no próximo recorte, no qual ela culpa o sistema escolar como causador de desânimo e desmotivação em ensinar.

(5) Eu gosto de dar aula, mas estou desanimada com o sistema, o salário. Não reprovamos o aluno, / tenho que ficar atrás de aluno. Eu não confessei, não expus, mas o sistema me deixa mu::ito desmotivada, / é o que me chateia - 09/07/2015.

Com base em Cavallari (2005), as representações do Outro presentes no discurso do professor possibilitam perceber deslocamentos de representações e vislumbrar as representações de si mesmo que são constitutivas da sua identidade. Por isso, o estudo das representações é relevante, uma vez que "assume um papel fundamental na (re)construção das identidades individuais, porque possibilita estabelecer uma relação entre o que está no imaginário social e a realidade" (TAVARES, 2002, p. 35-36).

Vemos nos movimentos da participante que ela começa o tempo para compreender ao procurar refletir e se interrogar, como faz no recorte (2) quando se interroga, porque eles conseguem e eu não? Ou no recorte (4), preciso aprender o caminho/ por onde começar/sabe? Assim, embora a participante ainda esteja a olhar para sua própria prática, começa a compreender a necessidade de se implicar e buscar conhecimentos e reconhecimento de seus pares para superar seus desafios em sala de aula.

\section{Considerações Finais}

Por meio dos dizeres da professora-participante, percebemos que ela se sente insatisfeita e que há um mal-estar, em relação ao seu próprio conhecimento linguístico da LI, com relação à prática metodológica, com a desvalorização do professor e com sua falta de autoridade e controle da disciplina em sala de aula. Ela também se compara e se identifica com os outros educadores, ora participantes do ConCol ora os colegas de trabalho, e, como sujeito desejante e participante de projeto de formação continuada, busca o saber de transformar e de lidar com os desafios da sala de aula. Desse modo, ela está à procura de uma completude que lhe falta, pois nos parece que Sofia busca estruturar o seu eu, ter uma identidade una, portanto ela estaria construindo um eu ideal, a fim de ter reconhecimento e amor dos alunos e dos colegas.

Além disso, assim como outros professores que participam de programas de educação continuada, a docente está entre o instante de olhar e o momento de compreender, ou seja, 
momento de se interrogar e buscar o aperfeiçoamento linguístico e metodológico que ela deseja. Entretanto, não podemos afirmar que Sofia chegará no estágio de concluir, de encontrar uma identidade profissional tida como ideal. Portanto, este estudo pode contribuir para problematizar a formação de professores, visto que abordamos questões relevantes que podem levar os educadores a refletirem e confrontarem-se com as significações que dão a si como professores e falantes da língua estrangeira.

\section{Referências bibliográficas}

ARAÚJO, M. G. Considerações sobre o narcisismo. Estudos de psicanálise. Aracaju, n. 34, Aracaju, 2010.

AUTHIER-REVUZ, J. Entre a transparência e a opacidade: um estudo enunciativo do sentido. Porto Alegre: EDIPUCRS, 2004.

BOGDAN, R.; BIKLEN, S. Características da investigação qualitativa. In: Investigação qualitativa em educação: uma introdução à teoria e aos métodos. Porto: Porto Editora, 1994.

BOLOGNINI, C. Z. A língua estrangeira como refúgio. In: CORACINI, M. J. (Org.) Identidade \& discurso: (des)construindo subjetividades. Campinas: Editora da Unicamp, 2003.

CABAS, C. G. O sujeito na psicanálise de Freud a Lacan - da questão do sujeito ao sujeito em questão. Jorge Zahar: Rio de Janeiro, 2009.

CAVALLARI, J. S. O discurso avaliador do sujeito-professor na constituição da identidade do sujeito-aluno. 2005. 220f. Tese de Doutorado. Instituto de Estudos da Linguagem da Universidade Estadual de Campinas, Campinas, 2005.

CELANI, M. A. A. (Org.). Professores e formadores em mudança. Relato de um processo de reflexão e transformação da prática docente. Campinas: Mercado de Letras, 2003.

CHEMOUNI, J. Educação. In: KAUFMANN, P. Dicionário enciclopédico de psicanálise: o legado de Freud a Lacan. Rio de Janeiro: Jorge Zahar Editor, 1996.

CHNAIDERMAN, M. Língua(s) - Linguagem(ns) - Identidade(s) - Movimento(s): uma abordagem psicanalítica. In: SIGNORINI, I. (Org.). Lingua(gem) e identidade: elementos para uma discussão no campo aplicado. Campinas: Mercado de Letras, 1998.

CLARK, H. H. O uso da linguagem. Cadernos de Tradução, n. 9, jan/mar. 2000.

COHEN, M. A. A questão do sujeito e algumas articulações possíveis: análise do discurso e psicanálise. In: LARA, G. M. P. et al. (orgs.). Análises do discurso hoje. Rio de Janeiro: Lucerna/Nova Fronteira, v. 1, 2008. 
CORACINI, M. J. (Org.) Identidade e discurso: (des)construindo subjetividades. Campinas: Editora da UNICAMP, 2003.

CORACINI, M. J. A celebração do outro: arquivo, memória e identidade. Campinas: Mercado de Letras, 2007.

CORACINI, M. J.; GHIRALDELlO, C. M. (Orgs.). Nas Malhas do Discurso: Memória, Imaginário e Subjetividade. Formação de professores (línguas materna e estrangeiras), leitura e escrita. Ed. 1, Campinas: Pontes editores, 2011.

DUFF, P. A. Case study research in applied linguistics. New York: Lawrence Erlbaum/Taylor \& Francis, 2008.

DUFF, P. A. How to carry out case study research. In: MACKEY A.; GASS, S. M. Research methods in second language acquisition. Malden: Wiley-Blackwell, 2012. http://dx.doi.org/10.1002/9781444347340.ch6

FERREIRA, M. C. L. A língua da análise de discurso: esse estranho objeto de desejo. In: . (Org.). I SEAD: Michel Pêcheux e Análise de Discurso: uma relação de nunca acabar. Ed. 1, v. 1, 2003.

FLORES, V. N. Linguística e Psicanálise: princípios de uma semântica da enunciação. Porto Alegre: EDIPUCRS, 1999.

FLORES, V. N. Princípios para a definição do objeto da linguística da enunciação. In: BARBISAN, L. B.; FLORES, V. N. (Orgs). Estudos sobre enunciação, texto e discurso. Letras de Hoje. Porto Alegre: EDIPUCRS, v. 36, n. 4, 2001.

FLORES, V. N.; TEIXEIRA, M. Introdução à linguística da enunciação. São Paulo: Contexto, 2005.

FOUCAULT, M. A arqueologia do saber (1969). Rio de Janeiro: Forense Universitária, 1986.

FOUCAULT, M. A ordem do discurso (1971). São Paulo: Loyola, 1996.

FREUD, S. Sobre o narcisismo: uma introdução. In: . Edição standard brasileira das obras psicológicas completas (1914). 1. Ed. Tradução Jayme Salomão, v. XIV. Rio de Janeiro: Imago, 1974.

FREUD, S. Ensaios sobre a histeria (1985). Obras Completas, v. 02, ed. Standard. Rio de Janeiro: Imago, 1996.

FREUD, S. Além do princípio do prazer (1920). Obras Completas, v. 18, ed. Standard. Rio de Janeiro: Imago, 1996b.

GRIGOLETTO, M. Lições do modelo: a escrita que engessa e a que mobiliza. In: RIOLFI, C. R.; BERTOLDO, V. H. O inferno da escrita: produção e psicanálise. Campinas: Mercados das Letras, 2011. 
HON, F. S. Deslocamentos identitários de professores no discurso sobre sua prática de avaliação no processo de educação continuada. 2009. 176f. Dissertação (Mestrado em Linguística Aplicada) - Faculdade de Letras. Universidade Federal de Minas Gerais, Belo Horizonte, 2009.

LACAN, J. O seminário, livro 17: O avesso da psicanálise (1969-1970). Rio de Janeiro: Zahar, 1992.

LACAN, J. Escritos (1966). Tradução Vera Ribeiro. Rio de Janeiro: Jorge Zahar, 1998.

LACAN, J. [1964]. O seminário, livro 11: os quatro conceitos fundamentais da psicanálise. Texto estabelecido por Jacques-Alain Miller; Trad. M. D. Magno. Rio de Janeiro: Jorge Zahar, 2008 .

LOURES, G. O manejo da transferência na formação de professores de inglês: um estudo de caso. 2014. 191f. (Tese de doutorado) Faculdade de Letras da Universidade Federal de Minas Gerais, Belo Horizonte, 2014.

MARIANI, B. S. C. Favela, ensino de português e escola: algumas histórias com a Rocinha. In: TEVES, N.; RANGEL, M. (Org.). Representação social e educação: temas e enfoques contemporâneos de pesquisa. Ed.1, São Paulo: Papirus, v.1, 1999.

MIRANDA, M. P.; SANTIAGO, A. L. As conversações e a psicanálise aplicada à educação: um estudo do mal-estar do professor e o aluno considerado problema, 2011. Disponível em: http://www.proceedings.scielo.br/pdf/lepsi/n8/a39n8.pdf. Acesso em 03 de abril de 2014.

MRECH, L. Psicanálise e educação: novos operadores de leitura. São Paulo: Pioneira Thomson Learning, 2003.

MULLER, L. S. A interação professor-aluno no processo educativo. Disponível em: http://www.usjt.br/proex/arquivos/produtos_academicos/276_31.pdf. Acesso em 08 de Janeiro de 2015.

NEVES, M. S. Processo discursivo e subjetividade: vozes preponderantes na avaliação da oralidade em língua estrangeira no ensino universitário. 2002. 276f. Tese (Doutorado em Linguística Aplicada) - Instituto de Estudos da Linguagem da Universidade Estadual de Campinas. Campinas, 2002.

NEVES, M. S.; REIS, V. S. O sujeito discursivo da avaliação de aprendizagem na educação e na pedagogia de línguas. In: BERTOLDO, E. S. (Org.). Ensino e aprendizagem de línguas e a formação do professor: perspectivas discursivas. São Carlos: Claraluz, 2009.

NEVES, M. S. A Conversação como pesquisa em projeto de educação continuada: 0 afetamento da psicanálise no ensino/aprendizagem de línguas. Projeto de Pesquisa para a Faculdade de Letras. Belo Horizonte: UFMG, 2014. 
NEVES, M. S.; HON, F. S.; REIS, V. S.; EVANGELISTA, H. A. Deslocamento identitários em relação à expectativa e à promessa de mudança na prática do ensino e da avaliação no projeto EDUCONLE. In: DUTRA. D. P.; MELLO, H. R. (Orgs.). Educação continuada: diálogos entre ensino, pesquisa e extensão. Campinas: Pontes Editores, v. 30, 2013.

OGILVE, B. Lacan: a formação do conceito de sujeito. Rio de Janeiro: Jorge Zahar Ed., 1991.

ORLANDI, E. Análise de discursos: princípios e procedimentos. Campinas: Pontes, 1999.

ORLANDI, E. O estado, a gramática, a autoria. Disponível em: http://www.unicamp.br/iel/hil/publica/relatos_04.html. Acesso em 09 de agosto de 2015.

PÊCHEUX, M. Análise automática do discurso. Tradução de Eni Orlandi. In: GADET, F.; HAK, T. (Orgs.). Por uma análise automática do discurso: uma introdução à obra de Michel Pêcheux. Ed. 2, Campinas: Unicamp, 1993.

PÊCHEUX,Michel. Semântica e Discurso. Uma Crítica à afirmação do óbvio. 3 ed. Campinas: Unicamp, 1997.

PÊCHEUX, M. O discurso: estrutura ou acontecimento. $3^{\text {a }}$. Edição. Tradução Eni P. Orlandi. Campinas: Pontes, 2002.

PEREIRA, M. R.; SANTIAGO A. L. B; LOPES, E. M. T. Apresentação do Dossiê Psicanálise e Educação. In: Educação em Revista, v. 25, n. 01, Belo Horizonte, 2009.

REVUZ, C. A lingual estrangeira entre o desejo de um outro lugar e o risco do exílio. In: SIGNORINI, I. (Org.) Lingua(gem) e identidade: elementos para uma discussão no campo aplicado. Campinas: Mercado de Letras, 1998.

RIOLFI, C. R. A. O Discurso que sustenta a prática pedagógica - Formação de professor de língua materna. 1999. 365 f. Tese (Doutorado em Linguística). Instituto de Estudos da Linguagem, Universidade Estadual de Campinas, São Paulo, 1999.

RIOLFI, C. R. A. A psicanálise e o professor que amarelou. In: Estilos da Clínica. USP Impresso, n. 2, v. 17, p. 344-358, jul./dez. 2012. http://dx.doi.org/10.11606/issn.19811624.v17i2p344-358

RIOLFI, C. R. A. A Língua Espraiada: responsabilidade subjetiva na formação de professores. Ed. 1. São Paulo: Mercado das Letras, 2015.

ROJO, R. H. R. Fazer Linguística Aplicada em perspectiva sócio-histórica: provação sofrida e leveza de pensamento. In: MOITA LOPES, L. P. Por uma Linguística Aplicada indisciplinar. São Paulo: Parábola Editorial, 2006.

ROUDINESCO, E.; PLON, M. Dicionário de Psicanálise. Rio de janeiro: Jorge Zahar Editor, 1998. 
SIGNORINI, I. Do residual ao múltiplo e ao complexo: o objeto a pesquisa em Linguística Aplicada. In: SIGNOTINI, I; CAVALCANTI, M. C. Linguística Aplicada e Trandisciplinaridade. Campinas, SP: Mercado de Letras, 2004.

SÓL, V. S. A. Trajetórias de professores de inglês egressos de um projeto de educação continuada: identidades em (des)construção. 2014. 259f. Tese (Doutorado em Linguística Aplicada) - Faculdade de Letras, Universidade Federal de Minas Gerais. Belo Horizonte, 2014.

SZUNDY, P. T. C. A; NICOLAIDES, C. A 'ensinagem' de línguas no Brasil sob a perspectiva da linguística aplicada: um paralelo com a história da ALAB. In: GERHARDT, A. F. L. M.; AMORIM, M. A. de. CARVALHO, A. M. Linguística aplicada e ensino: língua e literatura. Campinas: Pontes, 2013.

TAVARES, C. N. V. Entre o desejo e realização? Caminhos e (des)caminhos na aprendizagem de uma língua estrangeira. 2002. 201f. Dissertação (Mestrado em Linguística). Instituto de Letras e Lingüística, Universidade Federal de Uberlândia, Uberlândia, 2002 .

TAVARES, C. N. V. Identidade itine(r)rante: o (des)contínuo (des)apropriar-se da posição de professor de língua estrangeira. 2010. 279f. Tese (Doutorado em Linguística Aplicada). Instituto de Estudos da Linguagem da Universidade Estadual de Campinas. Campinas, 2010.

TEIXEIRA, M. Análise de Discurso e Psicanálise. Porto Alegre: EDIPUCRS, 2005.

YIN, R. K. Estudo de caso: planejamento e métodos. $5^{\text {a }}$ ed. Porto Alegre, RS: Bookman Editora Ltda, 2014. 